misprints, some unfortunately in the scientific names of insects and chemicals.

The reactions of both insects and crops to chemical treatment are so much influenced by climate, cropgrowing practices and varieties of crop grown that it would be almost impossible to write a book which should take account of all these factors. The fact that this one is written for the western part of the United States does not in any way prevent its being of great value to professional workers in other countries.

R. M. Greenslade

\section{PROPERTIES OF GLASS AND PLASTICS}

The Strength of Plastics and Glass

A Study in Time-Sensitive Materials. By Dr. R. N. Haward. Pp. viii $+245+16$ plates. (London: Cleaver-Hume Press, Ltd.; New York: Interscience Publishers, Inc., 1949.) 30s. net.

Physical Properties of Glass

By J. E. Stanworth. (Monographs on the Physics and Chemistry of Materials.) Pp. viii +224. (Oxford : Clarendon Press ; London : Oxford University Press, 1950.) 21s. net.

7 HESE two monographs reveal the remarkable difference which has developed in the progress of research on the strength or mechanical properties of glass, on one hand, and on viscous, electrical and mechanical properties, on the other.

The study of glass and plastics as solids has yielded a vast amount of experimental results on the strength properties of these materials. In the first book, Dr. R. N. Haward has carefully filtered and separated the available information and produced a source of factual knowledge and a comprehensive summary of the present position in this important field of investigation. It is clear, however, that theoretical work lags far behind the experimental results. Dr. Haward's book is therefore primarily one for reference to experimental techniques and results. From this aspect it should be of value not only to all those interested in the strength properties of plastics or glass, but also to students of the mechanical properties of materials in general. In addition to the reason advanced in the introductory chapter for linking glass and plastics, there might also have been added the combined use of these materials in laminated glass and their many notable similarities particularly at other than ordinary temperatures. A lack of appreciation of transformation phenomena in glasses and, in fact, in all vitreous substances leads, for example, to a somewhat hesitant discussion of the dilatometric transition point of plastics.

The equally excellent and noteworthy summary by J. E. Stanworth of research on those physical properties which have a bearing on present theories of the structure of inorganic glasses just as clearly demonstrates the lack of experimental work, particularly in the fields of viscosity, surface tension and magnetic properties. Theoretical speculations have developed and progressed in a most stimulating manner after the first impetus given by the fundamental ideas of Zachariasen and the experimental deductions of Warren and his co-workers.

A somewhat high proportion of Stanworth's monograph is also concerned with the strength of glass. This duplication is unfortunate, and these chapters could well have been omitted without diminishing the value and interest of the rest of the volume, or perhaps replaced by some information on, say, infrared spectra of glasses.

A defect common to both authors is the occurrence of instances where a more critical approach to theoretical speculations might have been taken. A point of similarity for which, however, both authors are to be commended lies in the clear and wellwritten manner in which the subjects, admittedly difficult, have been presented.

It is to be regretted that the rather high price of such important additions to the still somewhat meagre literature on the properties of glass may serve to keep them out of the possession of young technologists, on whom future progress in our know. ledge and insight into the structure of glasses, and liquids in general, depends.

H. Cole

\section{SCIENCE AND RELIGION}

Science, History and Faith

By Canon Richardson. Pp. vi +210 . (London, New York and Toronto: Oxford University Press, 1950.) 6s. 6d. net; School edition, 5s. net.

7 HIS book is uniform with three others which 1 are being published by the Oxford University Press under the title "A Primer of Christianity" and which deal respectively with the Beginning, the Furtherance and the Truth of the Gospel. Canon Richardson has written especially for those who are conscious of the great importance to-day of the scientific outlook and want to know how Christian faith and Christian theology can claim to be true when measured by scientific standards. The author will undoubtedly hold the audience he has in mind, and his own clarity of style carries with it a deep understanding of the problems involved. The first chapter, "The Knowledge of God", is followed by "Science, Religion and Philosophy", designed for those specially interested in science. The second chapter is divided into parts dealing with the scientific method, the comparative study of science, and the science of theology. The theme is well thought out and is a fair statement of the relation between science and theology. The latter is introduced as "the scientific discipline which studies the phenomena presented by the existence of the Christian religionits faith, worship, and life-in history and to-day". The layman is helped to the understanding of philosophy by the explanation of terms such as 'naturalism'.

The author's handling of historical evidence is equally convincing, as is also his treatment of miracles. Space is found for discussion of the doctrine of the Trinity, salvation and eschatology. In a concluding section dealing with the preparatory character of this world, Canon Richardson makes a claim for education which is of special significance to-day: "education is the process by which minds are led to choose and cherish the truly valuable ends of life, not for the sake of profit or utility, or in order that the pupils may 'get on' in the world, but simply because they are the ends of life and valuable for their own sake...t there is a difference between education and propaganda: true education leads the pupil to seek and love value; propaganda deprives him of his freedom and tries to produce in him not a free choice but a mechanical reaction".

H. D. ANThony 